Journal of Animal and Veterinary Advances 11 (16): 3019-3022, 2012

ISSN: $1680-5593$

(C) Medwell Journals, 2012

\title{
Intrarenal Artery Autologous Mesenchymal Stem Cell Injection for Treatment of Chronic Glomerulonephritis in Cat
}

\author{
${ }^{1}$ Sheng-Chuan Lin, ${ }^{4}$ Tzong-Fu Kuo, ${ }^{5} \mathrm{Fu}-\mathrm{Jen}$ Huang, ${ }^{2}$ Tsung-Chou Chang and ${ }^{3}$ Yan-Der Hsuuw \\ ${ }^{1}$ Department of Tropical Agriculture and International Cooperation, \\ ${ }^{2}$ Department and Graduate Institute of Veterinary Medicine, \\ School of Veterinary Medicine, ${ }^{3}$ Department of Biological Science and Technology, \\ National Ping-Tung University of Science and Technology, Neipu, Pingtung, Taiwan \\ ${ }^{4}$ Department and Graduate Institute of Veterinary Medicine, \\ School of Veterinary Medicine, National Taiwan University, Taipei, Taiwan \\ ${ }^{5}$ School of Medicine, Chang Gung University, Gueishan, Taoyuan, Taiwan
}

\begin{abstract}
Chronic glomerulonephritis is a major cause of morbidity and mortality in feline chronic kidney diseases. Mesenchymal stem cells are multipotent stem cells found in the stroma of bone marrow, adipose tissue and umbilical cord. Mesenchymal stem cells can be induced to differentiate into a wide array of cells types including osteoblasts, chondrocytes, myocytes, adipocytes, endothelium and neuronal cells. The effects of mesenchymal stem cell therapy have been investigated in rodent chronic renal failure models including genetic disease, glomerulo-nephritis and experimentally-induced chronic kidney diseases. The purpose of this study was to assess the feasibility of intra-renal artery mesenchymal stem cells transfer in cat with chronic glomerulonephritis. Researchers, hypothesized that mesenchymal stem cells could be safely administered to cats with chronic glomerulo-nephritis. Intra-renal artery mesenchymal stem cells injection would improve the function of the injected kidney. This clinical result showed the optimal direction that the patient demonstrated blood urea nitrogen and creatinine improvement after intra-renal artery mesenchymal stem cells transfer.
\end{abstract}

Key words: Chronic glomerulonephritis, chronic kidney diseases, mesenchymal stem cells, stem cell therapy, uremia

\section{INTRODUCTION}

The progression of renal disease is characterized by the development of glomerulosclerosis and interstitial fibrosis. Patient with end stage renal disease have an increased risk of cardiovascular disease (Westerweel et al., 2007). The reduction of nephron mass leads to hypertrophy, hyperfiltration, systemic hypertension and glomerulosclerosis (Yokoo et al., 2007). The structural complexity of the kidney where resident cells need complex cellular interactions to produce urine any attempt to artificially grow or repair a kidney will need to have distinct structures including glomeruli, tubules, interstitium and vessels (Razzaque, 2008). In the mammals, partial nephrectomy stimulates hypertrophy of remaining tissue even in the contralateral kidney but not the generation of new nephrons (Imai and Iwatani, 2007). However whereas the resection of an adult kidney does not lead to the regeneration achieved in the liver the mammalian kidney shares with the majority of organs the ability to repopulate and repair structures that have sustained some degree of injury (Direkze et al., 2003). The advancement of stem cell biology has helped in designing stem cells as a therapeutic tool to accelerate tissue repair (Semedo et al., 2009). Stem cell therapy is becoming a more viable therapy for chronic kidney injury (Brodie and Humes, 2005; Lazzeri et al., 2007; Gross et al., 2009). Mesenchymal stem cells are good candidates for renal repair because nephrons are of mesenchymal origin (Imasawa et al., 2001; Kunter et al., 2006). Stem cells were delivered to the damaged kidney that might involve autologous or nonautologous stem cells from a variety of sources (Little, 2006). Mesenchymal Stem Cells (MSCs) commonly are defined as bone marrow Bderived fibroblast-like cells which have some specific surface markers can be selected by their adherence characteristics or cell markers positive selection. MSCs have the ability to differentiate along the three principal mesenchymal lineages: Osteoblastic, adipocytic and chondrocytic (Poulsom et al., 2001; Razzaque, 2008). Several studies

Corresponding Author: Yan-Der Hsuuw, Department of Biological Science and Technology,

National Pingtung University of Science and Technology Pingtung, Taiwan 1, Shuefu Road, Neipu, Pingtung, Taiwan 
have shown that the administration of Mesenchymal Stem Cells (MSCs) leads to the amelioration of kidney injuries (Gupta et al., 2002). Immune modulation and anti-apoptotic effects have been associated with this improvement, suggesting that MSCs can act through paracrine mechanisms (Little, 2006). Researchers used intra-renal artery autologous MSCs injection to halt fibrosis in a clinic case of feline CKD. Researchers paid attention to clinic renal function recovery after MSCs transplantation and demonstrated that these cells could halt the process of fibrosis with an improvement in renal function.

\section{MATERIALS AND METHODS}

Clinical monitoring: The experimental cat had been treated renal uremia for 1 year. The patient got worse gradually in couple months. Clinical signs included anorexia, appetite loss completely, vomiting, black stool and weakness. Urination was normal, urine crystal examination was negative. FeLv, FIV and feline heart worm were negative by IDEXX Snap kit. Chronic renal failure was diagnosed via abdominal echography, X-ray and blood biochemistry examinations. Stem cell therapy was recommended after histopathology and computed tomography examinations (Fig. 1: The shapes of both-side kidneys were shrunken (red arrow). The density of cortex area was increased and medulla was smaller. Fibrosis and chronic nephropathy were confirmed. There was no obstruction, crystal or mass in ureter and urinary bladder (green arrow). Lymphocyte infiltration was obviously distributed in interstitial area. Tubular enlargement and epithelium degeneration were in injury area widely. The fine structure of glomerulus was disappeared (black arrow). A lot of vacuoles appeared in the cortex area. The kidney function was damaged seriously, resulting in uremia). The results demonstrated chronic glomerulonephritis and kidney fibrosis. The cat underwent physical examination and routine blood work (CBC, serum biochemistry, urinalysis and determination of UPC) prior to MSC injection and on 7, 14, 21, 28 and 35 days after MSC injection.

Bone marrow aspiration: The cat was physically examined for body weight, eye condition, skin appearance and mucous CRT before anesthesia. Researchers used atropine, xylazine (Bayer, $2.2 \mathrm{mg} \mathrm{kg}^{-1}$ I.M) and Zoletil-50 (Virbac, $6 \mathrm{mg} \mathrm{kg}^{-1}$ I.M) for general anesthesia that was maintained with an inhalation of $2 \%$ isoflurane (Halocarbon) in the procedures. Researchers collected $10 \mathrm{~mL}$ of bone marrow from femurs stifle using a bone marrow needle.
Mesenchymal Stem Cell (MSC) culture and cell delivery: Bone marrow $(10 \mathrm{~mL})$ was aspirated from the femur stifle under general anesthesia. Bone marrow was prepared as described through RBC lysis and Lymphoprep separation (Axis-shield). Cells were cultured in low-glucose Dulbecco's modified Eagle's medium (Invitrogen) with $10 \% \mathrm{FBS}$ and $1 \%$ penicillin-streptomycin and incubated at $37^{\circ} \mathrm{C}$ in a humidified atmosphere with $5 \% \mathrm{CO}_{2}$. After 5 days of culturing, non-adherent cells were removed and adherent cells were incubated with CD 271-PE antibodies for $10 \mathrm{~min}$ followed by capture with anti-PE microbeads for $15 \mathrm{~min}$ at $4^{\circ} \mathrm{C}$ (Zhang et al., 2004). A MACS apparatus was used to collect the magnetically labeled cells which were then cultured in DMEM (Invitrogen) with 10\% MSC-qualified FBS (Invitrogen) and $1 \%$ penicillin-streptomycin and incubated at $37^{\circ} \mathrm{C}$ in a humidified atmosphere with $5 \% \mathrm{CO}_{2}$. After 7 days in culture, $15 \times 10^{4}$ cells were collected for transplantation. One intra-renal artery MSC injection was chose for cells

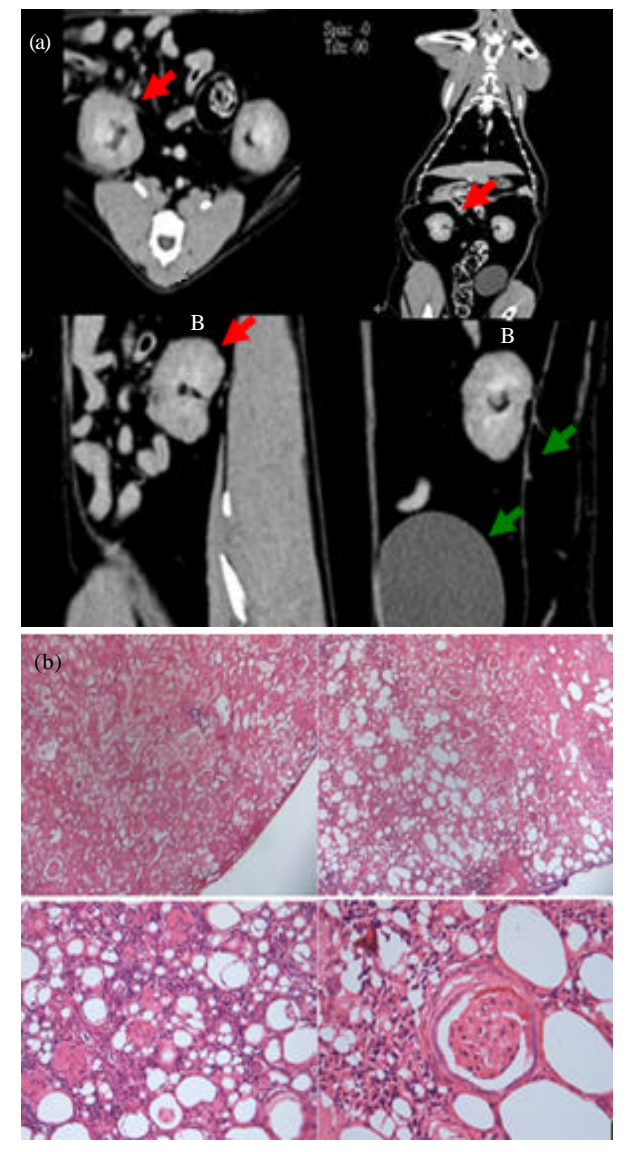

Fig. 1: a) Computed tomography examinations and b) histopathologic examinations demonstrated chronic glomerulonephritis and kidney fibrosis 
transplantation (Kunter et al., 2007). The BUN, creatinine and UP/UC ratio were measured to monitor the kidney function improvement.

\section{RESULTS AND DISCUSSION}

Mesenchymal stem cell and cell delivery: CD-271 positive MSCs were purified from femur stifle aspiration. These cells have a 10-100 higher proliferative capacity compared to MSCs isolated by plastic adherence. After purification and extension, $15 \times 10^{4}$ cells were collected for transplantation. MSCs were prepared in $1 \mathrm{~mL}$ of low-glucose Dulbecco's modified Eagle's medium (Invitrogen) with 1\% penicillin-streptomycin. One intrarenal artery MSC injection was chose for cells transplantation.

Monitoring of CBC, serum biochemistry before and after MSCs transplantation: The patient showed recovery after received MSC transplantation during 6 weeks. BUN was decreased from $113-67 \mathrm{mg} \mathrm{dL}^{-1}$ in 2 weeks. The spirit of patient was improved. BUN value was maintained from $90-67 \mathrm{mg} \mathrm{dL}^{-1}$ in 4 weeks. The value of serum creatinine was improved too. Creatinine value was decreased from 12-6.6 $\mathrm{mg} \mathrm{dL}^{-1}$. CKD caused patient anemia the condition was improved after MSCs transplantation. PCV was maintained between 14-17\% (Fig. 2: There was only one intra-renal artery injection. The condition persisted 4 weeks. The curve of creatinine and PCV values before and after MSCs transplantation. Creatinine value was decreased to $6.6 \mathrm{mg} \mathrm{dL}^{-1}$ after MSCs transplantation. The improvement persisted 3 weeks. The curve of PCV values before and after MSCs transplantation. The condition was maintained between 13-17\% after MSCs transplantation).

Chronic glomerulonephritis is a major cause of morbidity and mortality in feline and human Chronic Kidney Diseases (CKD) (Mohandas and Segal, 2010). Kidney transplantation is the only choice for CKD patients to recovery or long-term dialysis to maintain (Imai and Iwatani, 2007) but the chance is rare and induced rejection side-effect. Stem cell therapy provides another opportunity for chronic kidney disease patients (Zerbini et al., 2006). In this case study, researchers used autologous MSCs to repair or regenerate the damaged kidney tissue. In resulting, researchers found the clinical conditions were improved no matter on BUN, creatinine or patient spirit. The Urine Creatinine (UC) was measured before and after stem cell implantation. The UC is also improved from 53-36 $\mathrm{mg} \mathrm{dL}^{-1}$ but the UP (Urine Protein) remained at $21 \mathrm{mg} \mathrm{dL}^{-1}$ after stem cells transplantation. The UP/C ratio did not improve from 0.4-0.6. The effect lasted 4 weeks after one intra-renal artery injection. Partial nephrectomy stimulates hypertrophy of remaining tissue but not the generation of new nephrons. Kidney owns the ability to repopulate and repair structures that have suffered pathologic injury. This process, termed cellular repair, can promote proliferation of neighboring cells (Little, 2006). As a result, the kidney can undergo significant remodeling in response to acute damage (Lazzeri et al., 2007). However, autologous MSCs transplantation seems to have a limited potential for structural repair or true regeneration. Since, the kidney has the ability to regenerate following MSCs transplantation. Results showed the potential use of stem cell therapy in accelerating regenerative accelerating regenerative processes and improve clinical function of end-stage renal failure. Mesenchymal stem cells can differentiate into various renal cells including mesangial cells, tubular epithelial cells and podocytes (Sugimoto et al., 2006). Most of the chronic renal diseases
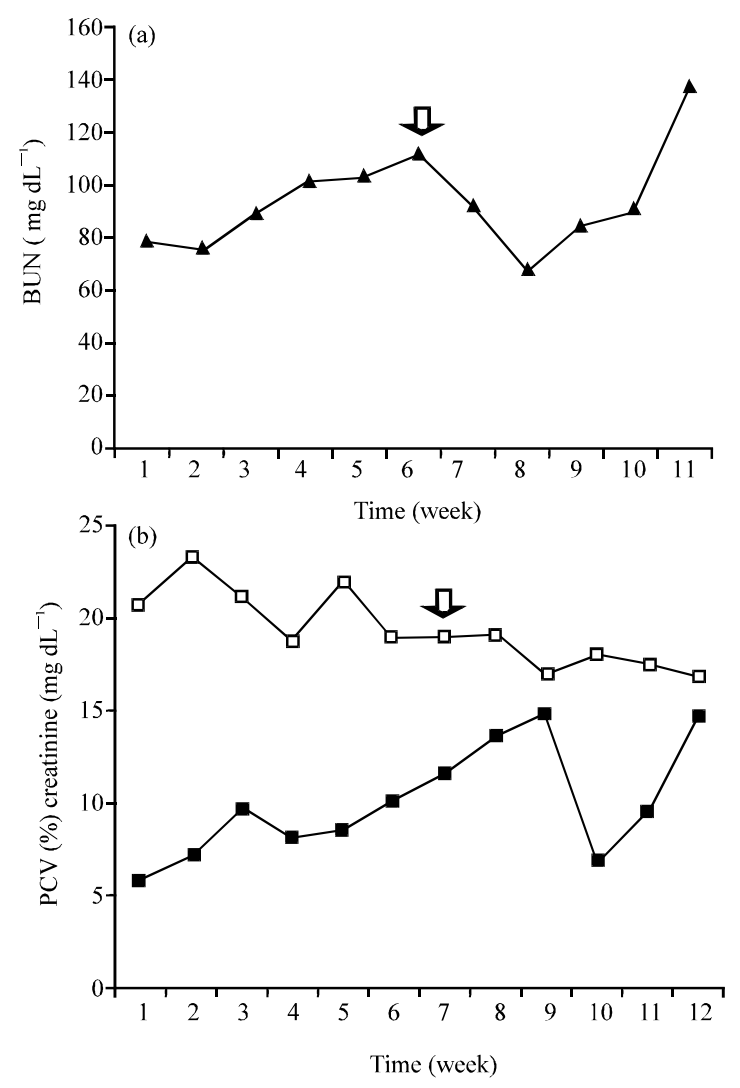

Fig. 2: a) The curve of BUN; b) PCV and creatinine values before and after MSCs transplantation. BUN values were decreased from 113-67 $\mathrm{mg} \mathrm{dL}^{-1}$ after MSCs transplantation ( $\mathbf{a}$ : creatinine, $\square$ : PCV, $\mathbb{U}$ : cell implantation) 
usually progress to irreversible renal failure. Stem cell therapy has potential in renal regenerative medicine and can be used to change the course of renal diseases to delay the progression of end-stage kidney failure (Terrier et al., 2006). Several possible mechanisms exist by which treatment with MSCs lead to this improvement. MSCs may secrete cytokines or growth factors to achieve this ability. Evidence suggests that a paracrine action is the most likely mechanism (Kunter et al., 2006; Imai and Iwatani, 2007). In general, this clinical trial demonstrated the possibility of chronic glomerulonephritis repair by autologous MACs transplantation. There was only one intra-renal artery injection. It is expected to operate the multi-injection in the same case or other pathway could be tried in future research.

\section{CONCLUSION}

This clinical trial provides important evidences that autologous mesenchymal stem cells therapy demonstrated the improvement of kidney function in feline CKD. The novel findings provide important new insights into the therapy of chronic kidney failure with stem cell transplantation.

\section{REFERENCES}

Brodie, J.C. and H.D. Humes, 2005. Stem cell approaches for the treatment of renal failure. Pharmacol. Rev., 57: 299-313.

Direkze, N.C., S.J. Forbes, M. Brittan, T. Hunt and J. Rosemary et al., 2003. Multiple organ engraftment by bone-marrow-derived myofibroblasts and fibroblasts in bone-marrow-transplanted mice. Stem Cells, 21: 514-520.

Gross, O., D.B. Borza, H.J. Anders, C. Licht and M. Weber et al., 2009. Stem cell therapy for Alport syndrome: the hope beyond the hype. Nephrol Dial Transplant, 24: 731-734.

Gupta, S., C. Verfaillie, D. Chmielewski, Y. Kim and M.E. Rosenberg, 2002. A role for extrarenal cells in the regeneration following acute renal failure. Kidney Int., 62: 1285-1290.

Imai, E. and H. Iwatani, 2007. The continuing story of renal repair with stem cells. J. Am. Soc. Nephrol., 18: 2423-2428.

Imasawa, T., Y. Utsunomiya, T. Kawamura, Z. Yu and R. Nagasawa et al., 2001. The potential of bone marrow-derived cells to differentiate to glomerular mesangial cells. J. Am. Soc. Nephrol., 12: 1401-1409.

Kunter, U., S. Rong, P. Boor, F. Eitner and G. Muller-Newen et al., 2007. Mesenchymal stem cells prevent progressive experimental renal failure but maldifferentiate into glomerular adipocytes. J Am. Soc. Nephrol., 18: 1754-1764.
Kunter, U., S. Rong, Z. Djuric, P. Boor, G. Muller-Newen, D. Yu and J. Floege, 2006. Transplanted mesenchymal stem cells accelerate glomerular healing in experimental glomerulonephritis. J. Am. Soc. Nephrol, 17: 2202-2212.

Lazzeri, E., C. Crescioli, E. Ronconi, B. Mazzinghi and C. Sagrinati et al., 2007. Regenerative potential of embryonic renal multipotent progenitors in acute renal failure. J. Am. Soc. Nephrol., 18: 3128-3138.

Little, M.H., 2006. Regrow or repair: Potential regenerative therapies for the kidney. J. Am. Soc. Nephrol., 17: 2390-2401.

Mohandas, R. and M.S. Segal, 2010. Endothelial progenitor cells and endothelial vesicles-what is the significance for patients with chronic kidney disease. Blood Purif, 29: 158-162.

Poulsom, R., S.J. Forbes, K. Hodivala-Dilke, E. Ryan and S. Wyles et al., 2001. Bone marrow contributes to renal parenchymal turnover and regeneration. $\mathrm{J}$. Pathol., 195: 229-235.

Razzaque, M.S., 2008. Can patient-specific stem cell therapy enhance renal repair? Nephrol. Dial Transplant, 23: 1826-1830.

Semedo, P., M. Correa-Costa, M.A. Cenedeze, D.M.A.C. Ma and M.A.D. Reis et al., 2009. Mesenchymal stem cells attenuate renal fibrosis through immune modulation and remodeling properties in a rat remnant kidney model. Stem Cells, 27: 3063-3073.

Sugimoto, H., T.M. Mundel, M. Sund, L. Xie, D. Cosgrove and R. Kalluri, 2006. Bone-marrow-derived stem cell repair basement membrane collagen defects and reverse genetic kidney disease. PNAS, 103: 7321-7326.

Terrier, B., D. Joly, D. Ghez, B. Knebelmann, F. Fakhouri and A. Hummel, 2006. Reversible paraparesis in multiple myeloma with renal failure. Nephrol. Dial Transplant, 21: 1439-1440.

Westerweel, P.E., I.E. Hoefer, P.J. Blankestijn, P. Bree and D. Groeneveld et al., 2007. End-stage renal disease causes an imbalance between endothelial and smooth muscle progenitor cells. Am. J. Physiol. Renal. Physiol., 292: F1132-F1140.

Yokoo, T., A. Fukui and E. Kobayashi, 2007. Application of regenerative medicine for kidney diseases. Organogenesis, 3: 34-43.

Zerbini, G., L. Piemonti, A. Maestroni, G. Dell'Antonio and G. Bianchi, 2006. Stem cells and the kidney: A new therapeutic tool? J. Am. Soc. Nephrol., 17: S123-S1 26.

Zhang, S., D. Wang, Z. Estrov, S. Raj, J.T. Willerson and E.T.H. Yeh, 2004. Both cell fusion and transdifferentiation account for the transformation of human peripheral blood cd34-positive cells into Cardiomyocytes in vivo. Circulation, 110: 3803-3807. 